\title{
Adjusting growth standards for fetal sex improves correlation of small babies with stillbirth and adverse perinatal outcomes: A state-wide population study
}

\author{
Natasha Pritchard ${ }^{1}$, Susan Walker ${ }^{1}$, Stephen Tong ${ }^{1}$, and Anthea C. Lindquist ${ }^{1}$ \\ ${ }^{1}$ Mercy Hospital for Women
}

November 22, 2021

\begin{abstract}
Objective: Identify the proportion of infants reclassified if sex-specific birthweight charts were used, and if this reclassification has an impact on the correlation between birthweight centile and adverse perinatal outcome. Design: Retrospective cohort study Setting: Victoria, Australia. Population: All infants born from 2005-2015 (529,261) Methods: We applied GROW centiles, either adjusted or unadjusted for fetal sex. We compared proportions of small for gestational age (SGA, <10th centile) infants, then the populations of males considered small only by sex-specific charts and females considered small only by unadjusted charts. Main Outcome Measures: Stillbirth, combined perinatal mortality, NICU admissions, Apgars $<7$ at 5 minutes, emergency caesarean sections. Results: Of those <10th centile by unadjusted charts, $39.6 \%$ were male, and $60.5 \%$ female. Using sex-specific charts, $50.3 \%<10$ th centile were male and $49.7 \%$ female. $9,449(19.2 \%)$ females that were SGA according to unadjusted charts were appropriate for gestational age (AGA, $>10$ th- $<90$ th centile) using sex-specific charts. These reclassified newborn females were not at increased risk of adverse outcomes compared with an AGA infant, but were at increased risk of being iatrogenically delivered for suspected growth restriction (RR 4.90, 95\% CI 4.39-5.48). 8,048 male infants were reclassified as SGA by sex-specific charts (25\% SGA increase). Compared with AGA infants, these reclassified male newborns were at greater risk of stillbirth (RR 1.94, 95\% CI 1.30-2.90) and all other adverse perinatal outcomes. Conclusions: Sex-specific growth standards classify a new high-risk cohort of male infants as SGA, and exclude a cohort of females, whose risk is no greater than appropriately grown infants.
\end{abstract}

\section{Hosted file}

Fetal_Sex_Customisation_Project_Manuscript.docx available at https://authorea.com/users/ 436629/articles/546480-adjusting-growth-standards-for-fetal-sex-improves-correlationof-small-babies-with-stillbirth-and-adverse-perinatal-outcomes-a-state-wide-populationstudy 

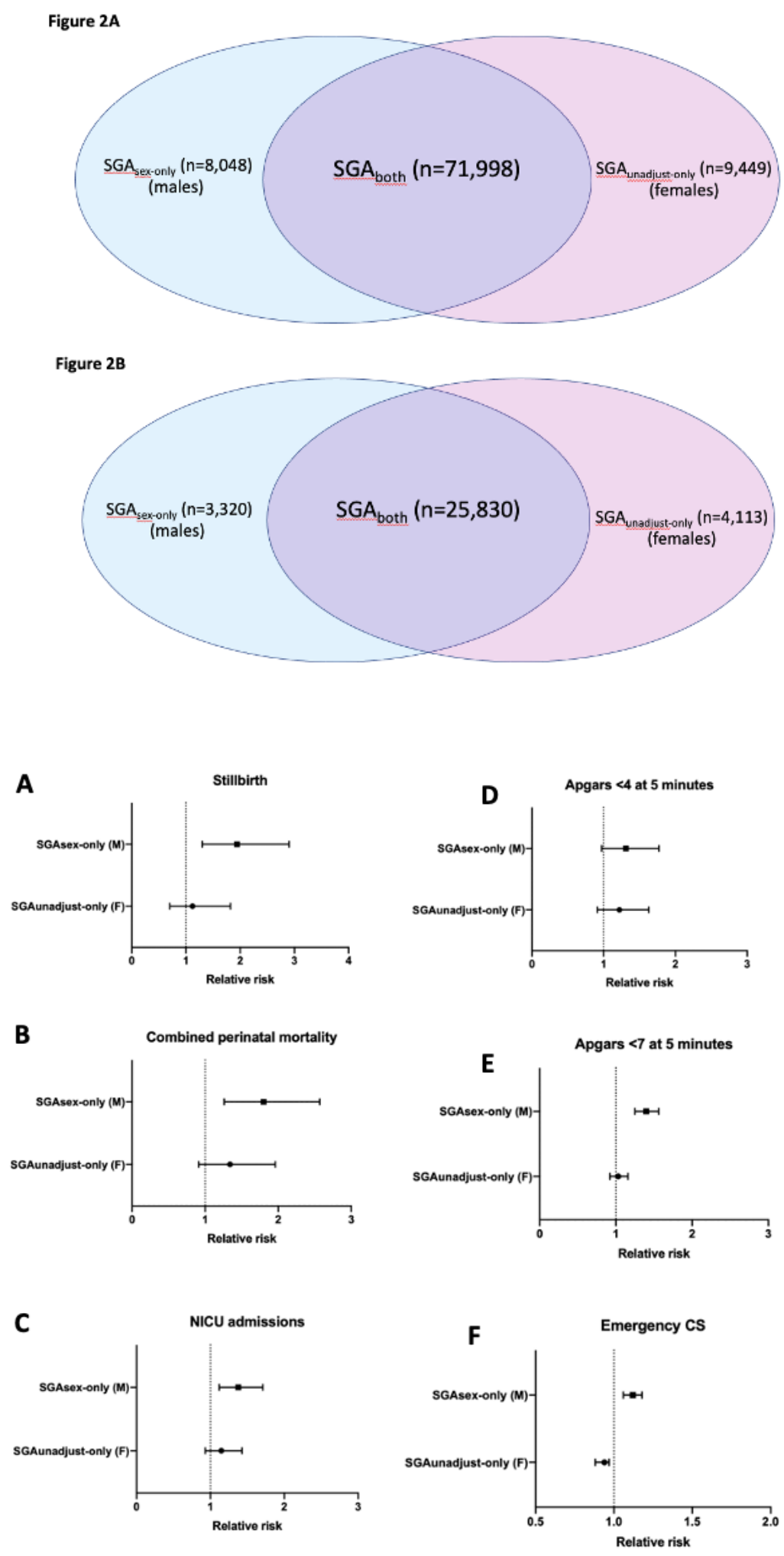

Figure 3 